\title{
Engaging students emotionally: the role of emotional intelligence in predicting cognitive and affective engagement in higher education
}

Rebecca Maguire, Arlene Egan, Philip Hyland \& Phil Maguire

To cite this article: Rebecca Maguire, Arlene Egan, Philip Hyland \& Phil Maguire (2017) Engaging students emotionally: the role of emotional intelligence in predicting cognitive and affective engagement in higher education, Higher Education Research \& Development, 36:2, 343-357, DOI: 10.1080/07294360.2016.1185396

To link to this article: https://doi.org/10.1080/07294360.2016.1185396

\section{曲 Published online: 22 May 2016.}

\section{Submit your article to this journal $\llbracket$}

Шll Article views: 1228

View Crossmark data ¿

Citing articles: 6 View citing articles $\square$ 


\title{
Engaging students emotionally: the role of emotional intelligence in predicting cognitive and affective engagement in higher education
}

\author{
Rebecca Maguire $^{a}$, Arlene Egan $^{a}$, Philip Hyland ${ }^{a}$ and Phil Maguire ${ }^{b}$ \\ ${ }^{\mathrm{a} S}$ School of Business, National College of Ireland, Dublin, Ireland; ${ }^{\mathrm{b}}$ Department of Computer Science, Maynooth \\ University, Maynooth, Ireland
}

\begin{abstract}
Student engagement is a key predictor of academic performance, persistence and retention in higher education. While many studies have identified how aspects of the college environment influence engagement, fewer have specifically focused on emotional intelligence (EI). In this study, we sought to explore whether EI could predict cognitive and/or affective engagement in a sample of undergraduate psychology students in Ireland. Ninety-one students completed two forms of the student engagement instrument, rating current engagement and retrospective secondary school engagement, along with the trait El (TEI) questionnaire. After controlling for academic ability, gender and school engagement, multiple regression analyses found TEl to be a positive predictor of both cognitive and affective engagement. Previous academic performance acted as an additional predictor of cognitive engagement, while retrospective affective school engagement predicted current affective engagement. These results suggest that interventions aimed at increasing El may have positive implications for many aspects of student engagement, and hence performance at third level.
\end{abstract}

\section{ARTICLE HISTORY}

Received 2 September 2015

Accepted 14 April 2016

\section{KEYWORDS}

Cognitive and affective engagement; higher education; Ireland; student engagement; trait emotional intelligence

\section{Introduction}

Student engagement is often cited as the most crucial factor in predicting educational success, with a wealth of research aimed at determining how best to foster this in higher education (Grier-Reed, Appleton, Rodriguez, Ganuza, \& Reschly, 2012). Low engagement is considered a key risk factor in student dropout and lack of persistence at both second level (i.e., in secondary/high school) and third level (i.e., in college/university) (Quaye \& Harper, 2014), with engagement consequently viewed as essential for student learning (Finn \& Zimmer, 2012). Within higher education, focus is often placed on modifying external factors, such as teaching and learning strategies, as a means of increasing engagement (Kuh, Kinzie, Schuh, \& Whitt, 2005). Nevertheless, when understanding predictors of engagement, it is important to acknowledge that student characteristics play a role in guiding this process. In particular, a student's level of emotional intelligence (EI) may be a significant factor, especially given its associations with academic performance 
(Perera \& DiGiacomo, 2013). In this paper, we investigate whether EI can predict different aspects of student engagement, namely cognitive and affective engagement, which in turn may inform interventions intended to increase persistence in third level.

\section{Understanding engagement}

The importance of engagement is well documented (Carini, Kuh, \& Klein, 2006), with clear associations observed between engagement and grades both at second (Reschly \& Christenson, 2006) and third levels (Kuh, Cruce, Shoup, Kinzie, \& Gonyea, 2008). Beyond academic gains, increased engagement can lead to benefits in numerous domains, ranging from skill development and competence, to enhanced psychological well-being and more positive views of self (Quaye \& Harper, 2014). Kuh and colleagues (2008) note that engagement can compensate for previous performance by enhancing grades and persistence throughout higher education, regardless of past academic results. However, while its importance is undisputed, a certain amount of debate surrounds the exact nature of engagement and its influences (Zepke, 2015).

Engagement is traditionally conceptualised as the effort students direct towards their learning (Pascarella \& Terenzini, 2005). This is typically manifested as participation in educationally effective practices, both within and/or outside the college environment (Quaye \& Harper, 2014). In recent years, the meaning of engagement has been expanded beyond examining the effort that students deploy in their learning activities, to how the institution adapts its resources and teaching strategies to encourage participation (Kuh, 2007). Thus, engagement is no longer viewed as simply an attribute of the student, but as a product of the wider social and cultural context (Christenson, Reschly, \& Wylie, 2012; Zepke, 2015) and, as such, is amenable to intervention at the institutional level.

Many researchers now recognise the multidimensional nature of engagement, with Appleton, Christenson, Kim, and Reschly (2006) reporting four distinct, yet interrelated, aspects: academic, behavioural, cognitive and affective (see also Fredricks, Blumenfeld, \& Paris, 2004). While the latter two aspects may be objectively observed in terms of completion of assignments, attendance and class participation, cognitive and affective engagement are more subjective, relating to students' perceptions of their learning and support. Affective engagement comprises feelings of belongingness and relatedness to those in college, while cognitive engagement entails the psychological investment students place in their academic work, their educational goals and feelings of control (Lawson \& Lawson, 2013). Thus, engagement involves more than just participation in educational activities: it also involves feelings and sense making (Harper \& Quaye, 2009).

Lack of engagement in either the cognitive and/or affective domains may offer an explanation for the two core difficulties experienced when students transition to third level, namely problems in academic or social aspects of college (McCoy, Smyth, Watson, \& Darmody, 2014). Since difficulties in either of these areas can result in student dropout, a greater understanding of what leads to low cognitive and affective engagement is merited so as to inform best practice in higher education (Drennan et al., 2014). 


\section{Predictors of engagement}

Understanding what drives students to engage in higher education has been the focus of much research investigation, with a propensity of studies appearing in the last decade (Zepke, 2015). Although engagement has a developmental path from second to third level (Finn, 1989), this characteristic is modifiable, with variations observed across different time periods and cohorts (Finn \& Zimmer, 2012). While academic ability may play a role in progression (McCoy \& Byrne, 2011), prior performance at second level does not necessarily predict engagement at third level. Kuh and colleagues (2008), for example, suggest that engagement in college can act as a protective factor for historically poor performing students. While many studies illustrate the importance of aspects of the college environment in facilitating engagement, such as faculty-student contact and collaborative learning (Umbach \& Wawrzynski, 2005), fewer have specifically focused on how pre-existing student characteristics facilitate, or impede, engagement in educational settings.

One characteristic which has received a lot of attention with regard to performance and engagement is that of gender. While gender gaps are narrowing in further education, Sax (2008) notes that males fare worse than females across a range of educational outcomes, a pattern rooted in second-level education. In Ireland, females outnumber males in college, consistently outperforming them in a number of domains (Mooney, Patterson, O'Connor, \& Chantler, 2010). Furthermore, a recent OECD (2015) report, including Irish data, found young males as significantly more likely to emerge from education with lower academic achievement and skills attainment than their female counterparts. This discrepancy may be due to differences in engagement, a view supported by Kinzie and colleagues (2007) who note women are more likely to participate in educationally purposive activities and devote greater time and effort to challenging tasks. This may explain why they are more likely to complete third-level education and pursue graduate studies (Marrs, Sigler, \& Brammer, 2012). In the current study, we seek to investigate whether gender differences exist in either cognitive and/or affective engagement; however, the key focus of this paper is to investigate the role of EI in predicting these components.

\section{Emotional intelligence}

Emotions experienced in third level are known to influence numerous aspects of student perceptions, including satisfaction and institutional loyalty (White, 2013) as well as students' views on their learning and assessment (Crossman, 2007). Consequently, researchers are developing an awareness of the importance of EI in education (Mortiboys, 2013). Over the past number of decades, EI has become 'one of the most visible and high-profile constructs in individual difference research' (Zeidner, Roberts, \& Matthews, 2008, p. 64), receiving much attention in the areas of training, development and performance.

Following Goleman's (1995) initial theory, the current consensus is to consider EI from two distinct theoretical perspectives (Sanchez-Ruiz, Mavroveli, \& Poullis, 2013). The first views EI as an ability, possibly linked with general intelligence (Mayer, Roberts, \& Barsade, 2008). This ability EI involves the capacity to perceive, express, understand, analyse and assimilate emotion in thought, as well as being able to reflect on, regulate, and promote emotional and intellectual growth (Mayer \& Salovey, 2007). While typically assessed via 
cognitive-emotional ability tasks, the second perspective, trait EI (TEI) is assessed via selfreport measures, as it is more concerned with a person's own perception of their emotional characteristics, as well as their feelings of self-efficacy (Goleman, 1995; Petrides \& Furnham, 2001). Petrides (2011, p. 657) accordingly describes TEI as 'a constellation of self-perceptions located at the lower end of personality hierarchies', with Perera and DiGiacomo (2013) viewing this as the typical patterns of emotional regulation, perception and expression within an individual. Given the greater association between TEI and academic performance (Perera \& DiGiacomo, 2013; Sanchez-Ruiz et al., 2013) and the suggestion of a strong relationship between TEI and job performance (Joseph, Jin, Newman, \& O'Boyle, 2015), we chose to adopt this perspective, rather than ability EI, in the current study.

While researchers are beginning to recognise the role that TEI plays in academic performance (Parker, Summerfeldt, Hogan, \& Majeski, 2004; Saklofske, Austin, Mastoras, Beaton, \& Osborne, 2012; Sanchez-Ruiz et al., 2013), the specific mechanism for explaining this relation remains unclear (Perera \& DiGiacomo, 2013). Mavroveli and SánchezRuiz (2011) note EI should not be directly involved in academic performance, given that it is an affective characteristic. However, we hypothesise that this link may be explained in terms of enhanced engagement, both affective and cognitive. The role of EI in facilitating workplace engagement has recently been documented (Akhtar, Boustani, Tsivrikos, \& Chamorro-Premuzic, 2015), with a handful of studies identifying a relationship between EI and measures associated with engagement in academic settings (Durán, Extremera, \& Rey, 2004; Wurf \& Croft-Piggin, 2015). Parker, Hogan, Eastabrook, Oke, and Wood (2006) note that high EI promotes successful transition from second to third level, with those scoring higher in EI generally faring better in first year of college (McMillan, 2014). This is consistent with the finding that students' outlook, specifically having positive feelings before starting college, is more important in predicting adjustment than objective circumstances (Stevens \& Walker, 1996).

Although TEI might be expected to have positive implications for affective engagement, given that it is an affective characteristic (Mavroveli \& Sánchez-Ruiz, 2011), greater uncertainty surrounds the issue of whether cognitive engagement might be influenced in the same way. One possible theory is that cognitive engagement may be facilitated by TEI because of its association with greater perseverance and goal setting (e.g., Mount, Barrick, \& Strauss, 1999). Those with high TEI are also likely to exhibit enhanced selfregulation (Salovey, Bedell, Detweiler, \& Mayer, 2000), recognised as a crucial factor in persistence (Volet \& Mansfield, 2006). Indeed Perera and DiGiacomo (2013) note that a dispositional tendency towards self-control, a characteristic of those high in TEI, may serve as a key adaptive mechanism in a sustained academic goal-approach, thereby potentially leading to increases in cognitive engagement.

Beyond enhanced goal setting and self-regulation, EI has also been shown to buffer against stress and burnout in students (Durán et al., 2004). Saklofske and colleagues (2012) note that, given the role it plays in emotional regulation, EI may act as an explanatory variable for stress exhibited. Moreover, those with high TEI may be better at regulating emotions through cognitive reappraisal (Perera \& DiGiacomo, 2013), which would have benefits for cognitive as well as affective engagement. EI may hence be viewed as an important adaptive mechanism which enables students to handle stressors in their academic life (Saklofske et al., 2012). 


\section{Aims of the current research}

The current study aims to investigate the role of TEI in predicting affective and cognitive engagement, after controlling for the influence of gender, retrospective school engagement and prior academic ability. These variables were chosen based on their established associations with engagement and associated constructs. In light of the literature discussed above, we hypothesise that TEI will be a positive predictor of both (i) affective engagement and (ii) cognitive engagement, even after taking these factors into account.

\section{Method}

\section{Participants}

Ninety-one students ( 36 males; 55 females) from the National College of Ireland took part. All were enrolled in an undergraduate degree in psychology.

\section{Measures}

Two versions of the student engagement instrument (SEI) were adapted to assess both school and college engagement. Originally developed by Appleton and colleagues (2006), the SEI is a 33-item scale designed to measure both cognitive engagement (which entails control and relevance of school work, and future goals and aspirations), and affective engagement (which includes measures of teacher-student relationships, peer relationships and family support of learning). Participants rate their agreement with a series of statements on a four-point Likert scale (ranging from strongly agree to strongly disagree). Items are averaged to give rise to distinct subscales for affective and cognitive engagement, as well as a total engagement score.

While originally designed for a secondary school setting, the SEI has been successfully applied in third-level institutions (Grier-Reed et al., 2012) with good reliability and validity in a variety of populations (e.g., Appleton et al., 2006; Grier-Reed et al., 2012). For our study, the SEI was adapted to enable students to retrospectively rate their engagement at secondary level, as well as their current engagement in college. To reflect the language used in Irish institutions, this entailed substitution of certain words (e.g., 'lecturers' instead of 'teachers', 'college' instead of 'school'). Reliability for both versions of this instrument was strong, with Cronbach's alphas of .907 and .901 for school and college engagement, respectively.

To measure EI, the Trait Emotional Intelligence Questionnaire short form (TEIQueSF) was employed (Petrides \& Furnham, 2006). Based on the longer TEIQue (Petrides \& Furnham, 2001), this 30-item questionnaire comprises two items from 15 aspects of the original TEIQue (Petrides, 2009). Participants rated their agreement with items using a seven-point Likert scale. These items comprised both positively (e.g., 'Expressing my emotions with words is not a problem for me') and negatively (e.g., 'I tend to change my mind frequently') phrased statements. A total TEI score was computed with higher scores indicating higher levels of TEI. The reliability and validity of this instrument has been demonstrated previously (Cooper \& Petrides, 2010), with a Cronbach's alpha in our sample of .890 . 


\section{Procedure}

Following ethical approval, students were invited to take part in the study at the start of the academic year. All students provided basic demographic information (including age and gender) and Central Applications Office (CAO) points achieved in their Leaving Certificate examination which acted as a measure of academic ability before entering college (equivalent to GPA, points can range from 0 to 600 with higher points reflective of greater academic performance). Students filled out both versions of the SEI - one requiring them to retrospectively rate their engagement at school and a second to rate their current level of engagement at college - as well as the TEIQue-SF. Measures of engagement and TEI were taken at three time points throughout the academic year, enabling an average to be computed for each domain. This technique was adopted to give a more accurate reflection of overall engagement throughout the year, as opposed to that at a single time point.

\section{Statistical analysis}

Two multiple regression models were conducted, one for affective engagement and one for cognitive engagement. In addition to TEI, the four additional predictors were gender, prior academic performance (CAO points) and retrospective school engagement (both the cognitive and affective domains). Prior to carrying out these analyses, bivariate correlations were conducted using Pearson product-moment correlation coefficients to determine the relationship between all variables. None of the predictor variables were strongly associated, indicating that the assumption of multicollinearity was not violated. The data was thus deemed suitable for examination using multiple regression analysis. All the potential predictors were fitted simultaneously in the two linear regression models.

\section{Results}

\section{Descriptive statistics}

Descriptive statistics for the continuous variables are presented in Table 1. To allow for easy comparison, both school and college engagement and their associated subscales were standardised to scores of between 0 and 100. Results indicate that students reported high levels of both college and school engagement, as well as high levels of TEI.

A series of paired sample $t$-tests found that overall engagement, as well as affective and cognitive engagement, differed significantly between school and college $(p<.001)$. In all cases, current engagement in college was rated higher than past engagement in school.

Table 1. Descriptive statistics and reliability for all continuous variables.

\begin{tabular}{lrrrrr}
\hline & $M$ & SD & Range & Possible range & Cronbach's alpha \\
\hline College engagement & & & & & \\
Overall & 75.66 & 9.44 & $35-93$ & $0-100$ & .901 \\
Cognitive & 76.22 & 13.02 & $7-98$ & $0-100$ & $0-100$ \\
Affective & 80.93 & 9.65 & $52-98$ & & .907 \\
& & & & & $0-100$ \\
School engagement & & & $30-88$ & $0-100$ & $0-100$ \\
Overall & 64.65 & 12.13 & $24-86$ & $30-210$ & -890 \\
Cognitive & 59.05 & 14.70 & $30-95$ & $0-600$ & - \\
Affective & 68.77 & 13.80 & $97-194$ & & \\
TEl & 145.47 & 20.35 & $180-485$ & & \\
CAO points & 344.85 & 71.04 & & & \\
\hline
\end{tabular}


Table 2. Correlations between all variables.

\begin{tabular}{|c|c|c|c|c|c|c|c|}
\hline Variables & 1 & 2 & 3 & 4 & 5 & 6 & 7 \\
\hline 1. College Cog. Engagement & 1 & & & & & & \\
\hline 2. College Aff. Engagement & $0.56^{* *}$ & 1 & & & & & \\
\hline 3. TEI & $0.40^{* *}$ & $0.35^{*}$ & 1 & & & & \\
\hline 4. School Cog. Engagement & 0.03 & 0.13 & -0.02 & 1 & & & \\
\hline 5. School Aff. Engagement & -0.03 & $0.50^{* *}$ & -0.13 & $0.46^{* *}$ & 1 & & \\
\hline 6. CAO Points & 0.22 & 0.07 & -0.13 & $0.391^{*}$ & 0.01 & 1 & \\
\hline 7. Gender & 0.13 & 0.17 & -0.01 & $0.343^{*}$ & 0.02 & 0.20 & 1 \\
\hline
\end{tabular}

Statistical significance:

${ }^{*} p<.01$.

${ }^{* *} p<.001$.

\section{Bivariate correlations}

Results of the bivariate correlations are presented in Table 2. As can be seen, TEI was significantly related to cognitive engagement at college $(r=.40, p<.001)$, while both TEI $(r=.35, p<.01)$ and school affective engagement $(r=.46, p<.001)$ were significantly related to affective engagement at college. The two criterion variables of cognitive and affective engagement were also related $(r=.56, p<.01)$.

\section{Multiple regression analyses}

Standard multiple regression analysis was conducted to determine the effect of the predictor variables on college cognitive and affective engagement respectively. Preliminary analysis indicated no violations of the assumptions of normality, linearity and homoscedasticity.

The first regression model examining cognitive engagement was statistically significant $(F(4,51)=4.28, p=.005)$, and explained approximately $19 \%$ of variance in levels of cognitive engagement at college (see Table 3 ). TEI had the strongest predictive effect on cognitive engagement $(\beta=.44, p<.001)$, with $\mathrm{CAO}$ points also a significant predictor $(\beta=.30$, $p<.01)$. These results indicate that those with higher TEI and better CAO points were more likely to exhibit higher levels of cognitive engagement.

The second regression model examining affective engagement was also statistically significant $(F(4,51)=5.96, p=.001)$, and explained approximately $27 \%$ of variance in levels of affective engagement at college (Table 4 ). This was predicted by prior affective engagement at school $(\beta=.40, p<.001)$, and TEI $(\beta=.29, p<.01)$. These results suggest that those who had a higher affective engagement at school and higher levels of TEI were more likely to exhibit higher affective engagement.

Table 3. Multiple regression model predicting cognitive engagement at college.

\begin{tabular}{|c|c|c|c|c|c|c|c|}
\hline & $R^{2}$ & Adjusted $R^{2}$ & $\beta$ & $t$ & $B$ & SE & $\mathrm{Cl} 95 \%(B)$ \\
\hline Model & $.251^{*}$ & $.192^{*}$ & & & & & \\
\hline & & & $.44^{* *}$ & 3.55 & 0.28 & 0.08 & $0.12 / 0.43$ \\
\hline School Cognitive Eng. & & & -.12 & -0.90 & -0.11 & 0.12 & $-0.3 / 0.14$ \\
\hline CAO Points & & & $.30^{*}$ & 2.28 & 0.06 & 0.02 & $0.01 / 0.11$ \\
\hline Gender & & & .12 & 0.89 & 3.05 & 3.43 & $-3.83 / 9.92$ \\
\hline
\end{tabular}

Statistical significance:

${ }^{*} p<.01$.

${ }^{* *} p<.001$. 
Table 4. Multiple regression model predicting affective engagement at college.

\begin{tabular}{lllllllr}
\hline & $R^{2}$ & Adjusted $R^{2}$ & $\beta$ & \multicolumn{1}{c}{$t$} & \multicolumn{1}{c}{$B$} & \multicolumn{1}{c}{ SE } & \multicolumn{1}{c}{ CI 95\% (B) } \\
\hline Model & $.319^{* *}$ & $.265^{* *}$ & & & & & \\
TEI & & & $.29^{*}$ & 2.48 & 0.14 & .06 & $0.03 / 0.25$ \\
School Affective Eng. & & & $.40^{* *}$ & 3.43 & 0.28 & .08 & $0.12 / 0.45$ \\
CAO Points & & & .08 & 0.655 & 0.01 & .02 & $-0.02 / 0.04$ \\
Gender & & & .15 & 1.25 & 2.88 & 2.32 & $-1.76 / 7.53$
\end{tabular}

Statistical significance:

${ }^{*} p<.01$.

${ }^{* *} p<.001$.

\section{Discussion}

The primary aim of this study was to establish whether TEI would have any impact on affective and/or cognitive engagement after controlling for the influence of prior academic performance, school engagement and gender. We found that, while prior academic ability and retrospective school engagement played different roles in predicting the two aspects of engagement, TEI was the only significant predictor of both the affective and cognitive domains, supporting our hypotheses. These findings have interesting implications for the understanding of engagement in higher education, pointing to the important role that EI plays in this process.

\section{El and affective engagement}

The observation that students high in TEI reported higher levels of affective engagement is perhaps not surprising given that EI is considered an affective characteristic. The TEIQue requires individuals to reflect on aspects of their affective relationships and how they deal with social situations (Petrides, 2009). It follows that those scoring positively here might be more likely to report feeling closer to peers, family members and lecturers. It is important to note however that, although related, TEI and affective engagement are distinct constructs. While TEI centres on students' judgements of their own feelings, behaviours and emotional reactions, the affective component of the SEI requires assessments of how others (e.g., parents, teachers, peers) view and support them (Appleton et al., 2006).

The positive association between TEI and affective engagement may be explained by the skills in which those with high EI possess, or indeed the way they approach social situations. Perera and DiGiacomo (2015) highlight the importance of social support in college, noting that it is the perceived availability of this support that may explain the link between TEI and academic achievement. While we did not examine achievement here, this theory is consistent with our observed relationship between TEI and affective engagement. A plausible explanation is that those with higher TEI were more likely to report support of their learning in college (i.e., have higher affective engagement), possibly because they felt better equipped to interact with others in the first place.

In support of this view TEI has been shown to facilitate interaction (Ahles \& Bosworth, 2004), which is an important requirement for collaborative learning environments. Our findings suggest that TEI may have an effect on enhancing relationships, increasing affective engagement and, by extension, may facilitate successful integration into college life. This in turn may have positive implications on active learning in team settings (see also 
Farh, Seo, \& Tesluk, 2012). Any gains in learning are also likely to be further enhanced by the role of TEI in cognitive engagement, discussed further below.

\section{El and cognitive engagement}

Researchers are now gaining an appreciation of the way in which EI can be beneficial for learning in college (e.g., Mount et al., 1999; Sanchez-Ruiz et al., 2013) with a growing body of literature pointing to the role that TEI plays in academic performance (Durán et al., 2004; Habel, 2013; Perera \& DiGiacomo, 2013; Sanchez-Ruiz et al., 2013). Since grades and student retention are predicted by engagement (Quaye \& Harper, 2014), and in particular cognitive engagement (Appleton et al., 2006), our findings imply that TEI may be an important mechanism in influencing this link. We found that TEI was a stronger predictor of cognitive engagement than previous academic ability, which strengthens the evidence for the importance this characteristic plays in achievement at third level.

In order to explain its relationship with cognitive engagement, a closer look at the components of TEI is merited. Zeidner and colleagues (2008) highlight that a core aspect of TEI is emotional self-regulation, which may be particularly important in facilitating cognitive engagement. Self-regulation is recognised as central in learning and persistence (Wolters \& Taylor, 2012) with Saklofske and colleagues (2012) noting that emotional understanding and regulation support the adoption of a task-focused approach, a central element of cognitive engagement (see also Mega, Ronconi, \& De Beni, 2014). It is thus likely that those exhibiting higher TEI are better placed to regulate their behaviour leading to enhanced cognitive engagement and investment in their learning.

Personality differences associated with TEI could further explain this result. For example, Petrides $(2009,2011)$, found that students with high levels of TEI are less impulsive. This lower impulsivity may allow for enhanced stability and focus on longer-term goals (Petrides, 2011) which could explain our observed relation between TEI and cognitive engagement. Furthermore, increased self-efficacy is associated with higher TEI (Mikolajczak \& Luminet, 2008) which is well-established to relate to achievement (Caprara, Vecchione, Alessandri, Gerbino, \& Barbaranelli, 2011). All these components are likely to be crucial in explaining gains in cognitive engagement, though further research is merited to elucidate the nature of these relationships.

\section{Other predictors on engagement}

Beyond the important role of TEI, our findings reveal a number of additional predictors of engagement, albeit with different effects on the cognitive and affective domains. One clear pattern to emerge was that engagement at college, both cognitive and affective, was significantly higher than reported engagement at school. This is a positive finding given that the transition from second to third level is often reported as difficult for college students, both internationally (Hussey \& Smith, 2010; Kuh, 2007; McMillan, 2014), and in Ireland (McCoy et al., 2014). Furthermore, no gender differences in engagement were observed, an encouraging finding given that males are reported as being at greater risk of non-completion in higher education than females (Marrs et al., 2012; McGuinness et al., 2012).

Interestingly, retrospective school engagement had differing effects on college engagement with consistencies observed in the affective, but not the cognitive, domain. While it 
would be expected that family relationships remain constant during the transition from second to third level (McMillan, 2016), relationships with teaching staff and peers might be expected to differ given the change in context. The finding that those who feel supported by their peers and teachers at school are also more likely to report the same at college suggests that those with poorer quality relationships on entry to third level are at greater risk of low affective engagement. Since students without strong emotional connections at school are less likely to feel supported, they may in turn experience a range of problems at college (Finn \& Zimmer, 2012). We have already seen that this may be compounded by low TEI which highlights such students as a particularly high risk group. The importance of providing social support for students is now recognised, with Grootenboer (2010) specifically highlighting the need to foster affective development in university education (see also Townley et al., 2013).

Unlike affective engagement, there was no relationship observed between cognitive engagement at school and college, suggesting that the ways students approach their learning, as well as how they view their future educational goals, may change during the transition period. The finding that cognitive engagement at college was significantly higher than that in school suggests that students exert more effort and place a higher value in their college work than at second level, contradicting the assumption that engagement is firmly rooted in earlier patterns and strategies (Finn \& Zimmer, 2012). Of course, the increased engagement at third level may not simply be reflective of how students experience the transition. A myriad of factors can be at play in the transition to higher education including maturation, greater feelings of autonomy and enhanced motivation, all of which could result in higher cognitive engagement at third level. Whether or not this change is due to differences in the college environment, particular course of study, or other contextual factors, it suggests that students can overcome previously low levels of cognitive engagement at school to give rise to a more satisfying learning experience.

When examining the impact of prior academic performance on engagement, a different pattern of results emerged. While no association was found between results at second level and affective engagement at third level, CAO points did predict cognitive engagement. Although it would be expected that high performing students are more engaged (Kuh et al., 2008; McCoy \& Byrne, 2011), the weak relationship observed between these factors suggests that how students perform in school does not necessarily determine how engaged they will be in college. This mirrors Kuh and colleagues' (2008) finding that, while pre-college characteristics such as school grades do influence engagement, this relationship is attenuated when college experiences are taken into account (GrierReed et al., 2012). In line with our results, McCoy and colleagues (2014) found that half of Irish students do not feel their leaving certificate grades reflect their potential. Of our participants, only $36 \%$ stated their grades at school were a good reflection of their ability, compared to $80 \%$ answering the same question relating to college grades. This suggests that while certain aspects of engagement have a development progression (Finn, 1989), others, particularly cognitive aspects, are more amenable to change.

\section{Implications and applications of findings}

Increasing engagement is recognised as a core component of the current national strategy for Higher Education in Ireland (Hunt, 2011), a move which reflects international trends 
(Quaye \& Harper, 2014). Given the difficulties students often face in the transition from second to third level (McCoy et al., 2014), it is particularly important that higher education institutions identify the best means of enhancing engagement. Building on the theory of Perera and DiGiacomo (2013), our finding that TEI is associated with both cognitive and affective engagement suggests that interventions aimed at increasing EI may have positive effects, not only on engagement, but on academic performance and student retention. It also implies that affective as well as cognitive ability assessments may be better at determining success at college (Chamorro-Premuzic \& Furnham, 2003). Indeed, recent research has focused on enhancing academic and social learning by means of emotional development (Carthy \& McGilloway, 2015). Complementing such initiatives, we suggest that a useful strategy for achieving this goal might be to focus on enhancing self-regulatory capacities and to encourage realistic goal setting (Schippers, Scheepers, \& Peterson, 2015).

\section{Limitations and future research}

While this study offers an insight into the role of TEI in engagement, the relatively small sample size precludes any strong conclusions. The students in our sample were at varying stages of their degree, thus potentially limiting the generalisability of these results to other cohorts. Saklofske and colleagues (2012) note that, while high EI is very important for transition from school to college, where students also have to deal with a new socioemotional environment in addition to new academic challenges, it does not exert such a strong influence once the initial adjustment period is successfully negotiated. Further research is merited to clarify whether the relationship between TEI and engagement remains constant over time. An additional limitation is that this study involved only psychology students in Ireland, whereas those in different disciplines face different difficulties during college (McGuinness et al., 2012). It would be interesting to see if the effect of TEI on student engagement is consistent across various modes of study and student groups. Finally, it should also be acknowledged that our measure of school engagement was retrospective, whereas a longitudinal study tracking engagement from second to third level would offer greater insight into the exact trajectory of this relationship.

Nevertheless this study also had a number of strengths. Our measures of both engagement and EI were taken over the course of an academic year and therefore offer a diversified perspective on the relationship between these constructs, rather than being restricted to one time period. Few studies have systematically studied how both cognitive and affective engagement is predicted by EI, while controlling for retrospective experiences and performance. While this study entailed a small sample within the Irish higher education system, the issues experienced for students are similar in the majority of international institutions (OECD, 2015), with increasing engagement seen as a universal priority (Quaye \& Harper, 2014). Since there is a growing appreciation of the role that EI plays in academic performance, our findings offer some potential explanations for why this is the case. These findings offer an interesting platform for more in-depth exploration of the issues involved across different cohorts and disciplines.

\section{Conclusion}

Consistent with Kuh (2007), our results suggest that some understanding of pre-college experiences and dispositions is necessary to increase the odds that students will successfully 
navigate third level. While academic performance at second level plays a minor role in cognitive engagement, with school relationships impacting on affective engagement, we have found that EI is the most consistent predictor of both forms of engagement. Our results point to the importance of understanding a student's level of EI in determining how well they will adapt to college life. Interventions aimed at increasing students' metacognitive and self-regulatory abilities may be particularly advantageous in contributing to gains in both EI and engagement. This offers exciting directions for future research in higher education.

\section{Disclosure statement}

No potential conflict of interest was reported by the authors.

\section{References}

Ahles, C.B., \& Bosworth, C.C. (2004). The perception and reality of student and workplace teams. Journalism and Mass Communication Educator, 59(1), 41-59.

Akhtar, R., Boustani, L., Tsivrikos, D., \& Chamorro-Premuzic, T. (2015). The engageable personality: Personality and TEI as predictors of work engagement. Personality and Individual Differences, 73, 44-49. doi:10.1016/j.paid.2014.08.040

Appleton, J.J., Christenson, S.L., Kim, D., \& Reschly, A.L. (2006). Measuring cognitive and psychological engagement: Validation of the student engagement instrument. Journal of School Psychology, 44(5), 427-445.

Caprara, G.V., Vecchione, M., Alessandri, G., Gerbino, M., \& Barbaranelli, C. (2011). The contribution of personality traits and self-efficacy beliefs to academic achievement: A longitudinal study. British Journal of Educational Psychology, 81(1), 78-96.

Carini, R.M., Kuh, G.D., \& Klein, S.P. (2006). Student engagement and student learning: Testing the linkages. Research in Higher Education, 47(1), 1-32.

Carthy, A., \& McGilloway, S. (2015). 'Thinking outside the box': Promoting learning through emotional and social skills development. Procedia - Social and Behavioral Sciences, 191, 2655-2660. doi:10.1016/j.sbspro.2015.04.647

Chamorro-Premuzic, T., \& Furnham, A. (2003). Personality predicts academic performance: Evidence from two longitudinal university samples. Journal of Research in Personality, 37(4), 319-338.

Christenson, S.L., Reschly, A.L., \& Wylie, C. (2012). Handbook of research on student engagement. New York: Springer.

Cooper, A., \& Petrides, K.V. (2010). A psychometric analysis of the Trait Emotional Intelligence Questionnaire-Short Form (TEIQue-SF) using item response theory. Journal of Personality Assessment, 92(5), 449-457.

Crossman, J. (2007). The role of relationships and emotions in student perceptions of learning and assessment. Higher Education Research \& Development, 26(3), 313-327.

Drennan, J., O'Reilly, S., O'Connor, M., O’Driscoll, C., Patterson, V., Purser, L., et al. (2014). The Irish survey of student engagement. Engaging university students. Singapore: Springer Singapore.

Durán, A., Extremera, N., \& Rey, L. (2004). Self-reported emotional intelligence, burnout and engagement among staff in services for people with intellectual disabilities. Psychological Reports, 95(2), 386-390.

Farh, C.I., Seo, M.G., \& Tesluk, P.E. (2012). Emotional intelligence, teamwork effectiveness, and job performance: The moderating role of job context. Journal of Applied Psychology, 97(4), 890-900.

Finn, J.D. (1989). Withdrawing from school. Review of Educational Research, 59(2), 117-142.

Finn, J.D., \& Zimmer, K.S. (2012). Student engagement: What is it? Why does it matter? In S.L. Christenson, A.L. Reshley, \& C. Wylie's (Eds.), Handbook of research on student engagement (pp. 97-131). New York: Springer. 
Fredricks, J.A., Blumenfeld, P.C., \& Paris, A.H. (2004). School engagement: Potential of the concept, state of the evidence. Review of Educational Research, 74(1), 59-109.

Goleman, D. (1995). Emotional intelligence. New York: Bantam Books.

Grier-Reed, T., Appleton, J., Rodriguez, M., Ganuza, Z., \& Reschly, A.L. (2012). Exploring the student engagement instrument and career perceptions with college students. Journal of Educational and Developmental Psychology, 2(2), 85-96.

Grootenboer, P. (2010). Affective development in university education. Higher Education Research \& Development, 29(6), 723-737.

Habel, C. (2013). Teaching with emotional intelligence: A step by step guide for higher and further education professionals, by Alan Mortiboys. Higher Education Research \& Development, 32(3), 513-514.

Harper, S.R., \& Quaye, S.J. (2009). Beyond sameness, with engagement and outcomes for all. In S.J. Quaye \& S.R. Harper's (Eds.), Student Engagement in Higher Education (pp. 1-15). New York: Routledge.

Hunt, C. (2011). National strategy for higher education to 2030. Department of Education and Skills. Hussey, T., \& Smith, P. (2010). The trouble with higher education: A critical examination of our universities. New York: Routledge.

Joseph, D.L., Jin, J., Newman, D.A., \& O’Boyle, E.H. (2015). Why does self-reported emotional intelligence predict job performance? A meta-analytic investigation of mixed EI. Journal of Applied Psychology, 100(2), 298-342.

Kinzie, J., Gonyea, R., Kuh, G.D., Umbach, P., Blaich, C., \& Korkmaz, A. (2007). The relationship between gender and student engagement in college. Annual conference of the Association for the Study of Higher Education, Louisville, KY.

Kuh, G.D. (2007). What student engagement data tell us about college readiness. Peer Review, 9(1), 4-8.

Kuh, G.D., Cruce, T.M., Shoup, R., Kinzie, J., \& Gonyea, R.M. (2008). Unmasking the effects of student engagement on first-year college grades and persistence. The Journal of Higher Education, 79(5), 540-563.

Kuh, G., Kinzie, J., Schuh, J.H., \& Whitt, E.J. (2005). Student success in college: Creating conditions that matter. San Francisco: Jossey-Bass.

Lawson, M.A., \& Lawson, H.A. (2013). New conceptual frameworks for student engagement research, policy, and practice. Review of Educational Research, 83(3), 432-479.

Marrs, H., Sigler, E.A., \& Brammer, R.D. (2012). Gender, masculinity, femininity, and help seeking in college. Masculinities and Social Change, 1(3), 267-292.

Mavroveli, S., \& Sánchez-Ruiz, M.J. (2011). Trait emotional intelligence influences on academic achievement and school behaviour. British Journal of Educational Psychology, 81(1), 112-134.

Mayer, J.D., \& Salovey, P. (2007). Mayer-Salovey-Caruso emotional intelligence test. Multi-Health Systems.

Mayer, J.D., Roberts, R.D., \& Barsade, S.G. (2008). Human abilities: Emotional intelligence. Annual Review of Psychology, 59, 507-536. doi:10.1146/annurev.psych.59.103006.093646

McCoy, S., \& Byrne, D. (2011). 'The sooner the better I could get out of there': Barriers to higher education access in Ireland. Irish Educational Studies, 30(2), 141-157.

McCoy, S., Smyth, E., Watson, D., \& Darmody, M. (2014). Leaving school in Ireland: A longitudinal study of post-school transitions (ESRI Research Series No. 36).

McMillan, W. (2014). 'They have different information about what is going on': Emotion in the transition to university. Higher Education Research \& Development, 33(6), 1123-1135.

McMillan, W. (2016). 'People form their own support systems - like forming their own families': The role of parents and friends in the first year at dental school. European Journal of Dental Education, 20(2), 112-119.

McGuinness, S., Bergin, A., Kelly, E., McCoy, S., Smyth, E., \& Timoney, K. (2012). A study of future demand for higher education in Ireland. (RS30). Dublin: Economic and Social Research Institute.

Mega, C., Ronconi, L., \& De Beni, R. (2014). What makes a good student? How emotions, self-regulated learning, and motivation contribute to academic achievement. Journal of Educational Psychology, 106(1), 121-131. 
Mikolajczak, M., \& Luminet, O. (2008). Trait emotional intelligence and the cognitive appraisal of stressful events: An exploratory study. Personality and Individual Differences, 44(7), 1445-1453.

Mooney, O., Patterson, V., O'Connor, M., \& Chantler, A. (2010). A study of progression in Irish higher education. Dublin: HEA.

Mortiboys, A. (2013). Teaching with emotional intelligence: A step-by-step guide for higher and further education professionals. Abingdon: Routledge.

Mount, M.K., Barrick, M.R., \& Strauss, J.P. (1999). The joint relationship of conscientiousness and ability with performance: Test of the interaction hypothesis. Journal of Management, 25(5), 707-721.

OECD. (2015). Education at a glance 2015: OECD indicators. Paris: OECD. doi:10.1787/eag-2015-en

Parker, J.D., Hogan, M.J., Eastabrook, J.M., Oke, A., \& Wood, L.M. (2006). Emotional intelligence and student retention: Predicting the successful transition from high school to university. Personality and Individual Differences, 41(7), 1329-1336.

Parker, J.D., Summerfeldt, L.J., Hogan, M.J., \& Majeski, S.A. (2004). Emotional intelligence and academic success: Examining the transition from high school to university. Personality and Individual Differences, 36(1), 163-172.

Pascarella, E.T., \& Terenzini, P.T. (2005). How college affects students (Vol. 2). K.A. Feldman (Ed.). San Francisco, CA: Jossey-Bass.

Perera, H.N., \& DiGiacomo, M. (2013). The relationship of trait emotional intelligence with academic performance: A meta-analytic review. Learning and Individual Differences, 28, 20-33. doi:10.1016/j.lindif.2013.08.002

Perera, H.N., \& DiGiacomo, M. (2015). The role of trait emotional intelligence in academic performance during the university transition: An integrative model of mediation via social support, coping, and adjustment. Personality and Individual Differences, 83, 208-213. doi:10. 1016/j.paid.2015.04.001

Petrides, K.V. (2009). Technical manual for the Trait Emotional Intelligence Questionnaires (TEIQue) (1st ed., 4th printing). London: London Psychometric Laboratory.

Petrides, K.V. (2011). Ability and trait emotional intelligence. In T. Chamorro-Premuzic, S. von Stumm, \& A. Furham (Eds.), The Wiley-Blackwell Handbook of Individual Differences (pp. 656-678). Oxford: Wiley-Blackwell.

Petrides, K.V., \& Furnham, A. (2001). Trait emotional intelligence: Psychometric investigation with reference to established trait taxonomies. European Journal of Personality, 15(6), 425-448.

Petrides, K.V., \& Furnham, A. (2006). The role of trait emotional intelligence in a gender-specific model of organizational variables. Journal of Applied Social Psychology, 36(2), 552-569.

Quaye, S.J., \& Harper, S.R. (Eds.). (2014). Student engagement in higher education: Theoretical perspectives and practical approaches for diverse populations. New York: Routledge.

Reschly, A.L., \& Christenson, S.L. (2006). Prediction of dropout among students with mild disabilities: A case for the inclusion of student engagement variables. Remedial and Special Education, 27(5), 276-292.

Saklofske, D.H., Austin, E.J., Mastoras, S.M., Beaton, L., \& Osborne, S.E. (2012). Relationships of personality, affect, emotional intelligence and coping with student stress and academic success: Different patterns of association for stress and success. Learning and Individual Differences, 22(2), 251-257.

Salovey, P., Bedell, B.T., Detweiler, J.B., \& Mayer, J.D. (2000). Current directions in emotional intelligence research. Handbook of Emotions, 2(1), 504-520.

Sanchez-Ruiz, M.J., Mavroveli, S., \& Poullis, J. (2013). Trait emotional intelligence and its links to university performance: An examination. Personality and Individual Differences, 54(5), 658-662.

Sax, L.J. (2008). The gender gap in college: Maximizing the developmental potential of women and men. San Francisco: Jossey-Bass.

Schippers, M.C., Scheepers, A.W., \& Peterson, J.B. (2015). A scalable goal-setting intervention closes both the gender and ethnic minority achievement gap. Palgrave Communications, 1, 15014. doi:10.1057/palcomms.2015.14

Stevens, C.D., \& Walker, B.M. (1996). How residential college students adjust socially and emotionally to first year university. Higher Education Research \& Development, 15(2), 201-221. 
Townley, G., Katz, J., Wandersman, A., Skiles, B., Schillaci, M.J., Timmerman, B.E., et al. (2013). Exploring the role of sense of community in the undergraduate transfer student experience. Journal of Community Psychology, 41(3), 277-290.

Umbach, P.D., \& Wawrzynski, M.R. (2005). Faculty do matter: The role of college faculty in student learning and engagement. Research in Higher Education, 46(2), 153-184.

Volet, S., \& Mansfield, C. (2006). Group work at university: Significance of personal goals in the regulation strategies of students with positive and negative appraisals. Higher Education Research \& Development, 25(4), 341-356.

White, C.J. (2013). Higher education emotions: A scale development exercise. Higher Education Research \& Development, 32(2), 287-299.

Wolters, C.A., \& Taylor, D.J. (2012). In S.L. Christenson, A.L. Reshley, \& C. Wylie's. (Eds.), A selfregulated learning perspective on student engagement. In Handbook of research on student engagement (pp. 635-651). New York: Springer.

Wurf, G., \& Croft-Piggin, L. (2015). Predicting the academic achievement of first-year, pre-service teachers: The role of engagement, motivation, ATAR, and emotional intelligence. Asia-Pacific Journal of Teacher Education, 43(1), 75-91.

Zeidner, M., Roberts, R.D., \& Matthews, G. (2008). The science of emotional intelligence: Current consensus and controversies. European Psychologist, 13(1), 64-78.

Zepke, N. (2015). Student engagement research: Thinking beyond the mainstream. Higher Education Research \& Development, 1-13. Advance online publication. doi:10.1080/07294360. 2015 